\title{
Retos para lograr en México la cultura de la paz y los derechos humanos
}

\section{Challenges to Achieve in Mexico the culture of peace and human rights}

\section{Omar Huertas Díaz}

Abogado, doctorado (en curso) en Derecho, Universidad Nacional de Colombia (Col.); doctorado (en curso) en Ciencias de la Educación, Universidad Simón Bolivar (Col.); magister en Derecho Penal por la Universidad Libre (Col.); máster en Derechos Humanos, Estado de Derecho y Democracia en Iberoamérica por la Universidad de Alcalá, España; $M g$. en Educación por la Universidad Pedagógica Nacional (Col.); docente investigador Universidad Nacional de Colombia. Correoelectrónico: ohuertasd@unal.edu.co

Filiberto Eduardo R. Manrique Molina

Licenciado, maestro en Derecho; doctorado (en curso), Facultad de Derecho y Ciencias Sociales, Universidad Autónoma del Estado de Morelos, México.

Correo electrónico: lic.frmanrique@gmail.com

\section{Cecilia Correa de Molina}

Socióloga por la Universidad Autónoma del Caribe (Col.); licenciada en Psicopedagogía por la Corporación Universitaria de la Costa, magíster en Administración Educativa por la Universidad Externado de Colombia (Col.); especialista en Investigación Social y Educativa por el Convenio PIIE-ICFES; doctora en Ciencias Pedagógicas por el Instituto Nacional de Pedagogía Enrique José Varona, La Habana, Cuba; posdoctora en Currículo, Ciudadanía Gobernabilidad Social por el Centro de Investigación Posdoctoral CIPOST, Universidad Central de Venezuela. Correo electrónico: ccorrea@unisimonbolivar.edu.co

\section{José Saúl Trujillo González}

Abogado por la Universidad Santo Tomás. L.LM Universitat Konstanz y doctorando Universitat Konstanz, República Federal de Alemania. Docente investigador Polemos de la Corporación Universitaria de Sabaneta - Unisabaneta, Colombia. Correo electrónico: jose.trujillo@unisabaneta.edu.co

\section{Denisse Herreño Castellanos}

Abogada, especialista en Ciencia Politica por la Universidad Autónoma de Bucaramanga (Col.); magister en Estudios Políticos Aplicados (INAP-FIIAPP) Madrid, España; doctorado (en curso) en Estudios Politicos, Universidad Externado de Colombia (Col.); Investigación Universidad Santo Tomás Bucaramanga, Colombia. Correo electrónico: coord.investigaciones@ustabuca.edu.co

\begin{abstract}
Resumen
La violencia en México es el síntoma del fracaso de la cultura de la paz y los derechos humanos, la estrategia emprendida por los últimos dos gobiernos no ha dado resultados positivos, pues lejos de disminuir este tipo de violencia, la ha recrudecido. Indudablemente, tenemos que tomar la decisión y cambiar de paradigma, esto es encaminar al país por el sendero de los derechos humanos y una cultura sólida de la paz, para generar en la colectividad una actitud distinta. Los problemas de violencia deben ser manejados integralmente, pues para que la paz prospere se requiere de una cimentación profunda y sólida en la sociedad, en la que participan los gobiernos y la comunidad internacional en general, pues no hay duda de que la construcción de la paz es el requisito previo para el desarrollo económico, social y democrático de los pueblos.
\end{abstract}

Palabras clave: Paz, derechos humanos, cultura, violencia, constitución, derecho internacional, sociedad.

\begin{abstract}
Violence in Mexico, is the symptom of the failure of the culture of peace and human rights, the failure of the strategy undertaken by the last two governments have not given positive results, far from diminishing this type of violence has intensified. Undoubtedly, we have to make the decision and change the paradigm, this is putting the country on the path of human rights and a solid culture of peace, to generate in the community a different attitude. The problems of violence must be integrally managed, because for peace to flourish it requires a deep and solid foundation in society, in which participating governments and the international community at large, for there is no doubt that building peace it is the prerequisite for economic, social and democratic development of the peoples.
\end{abstract}

Keywords: Peace, human rights, violence, constitution, international law, society. 


\section{Résumé}

La violence au Mexique est le symptôme de l'échec de la culture de la paix et les droits humains, la stratégie entreprise par les deux derniers gouvernements n'a pas donné des résultats positifs à ce jour pour réduire ce type de violence, il a intensifié. Sans aucun doute, nous devons prendre la décision et un changement de paradigme qui met le pays sur la voie des droits de l'homme et d'une forte culture de la paix dans la communauté pour générer une attitude différente. Les problèmes de violence doivent être pleinement gérés, parce que pour la paix de prospérer nécessite une base solide et profonde dans la société, dans laquelle les gouvernements et la communauté internationale impliqués, car il n'y a pas de doute que la construction de la paix est la condition préalable au développement économique, social et démocratique des peuples.

Mots-clés: paix, droits de l'homme, la culture, la violence, constitution, le droit international, la société. 


\title{
Retos para lograr en México la cultura de la paz y los derechos humanos $^{*}$
}

\author{
Omar Huertas Díaz \\ Filiberto Eduardo R. Manrique Molina \\ Cecilia Correa de Molina \\ José Saúl Trujillo González \\ Denisse Herreño Castellanos
}

\section{INTRODUCCIÓN}

Pretendemos realizar un análisis que tienda a encontrar una solución viable a uno de los problemas que mayormente aquejan a las personas que viven en México y a todas aquellas que se encuentran en tránsito, me refiero a la situación de violencia generalizada, su impacto en los derechos humanos y en la cultura de la paz.

Pues de acuerdo con diversas organizaciones internacionales, el país se ha caracterizado por ser uno de los más violentos a nivel mundial y en donde más se comenten violaciones graves a los derechos de miles de personas. De acuerdo con The Global Peace Index, que clasifica a 162 países, cubriendo el 99,6\% de la población mundial, México se considera un país de baja seguridad (Peace, 2014), ello se justifica a que el país sigue enredado en el conflicto de la droga, y a un aumento en el número de responsables de seguridad interna.

* Artículo de investigación resultado de la estancia de investigación del Doctorado en Ciencias de la Educación de la Universidad Simón Bolívar 2014-2015 en la Universidad Autónoma del Estado de Morelos- México en colaboración con el Grupo de Investigación Escuela de Derecho Penal Nullum Crimen Sine Lege Un de la Universidad Nacional de Colombia, Grupo de Investigación Religación Educativa Compleja RELEDUC, de la Universidad Simón Bolívar de Barranquilla; Grupo de Investigación Polemos de la Corporación Universitaria de Sabaneta Unisabaneta. Grupo de Investigación Estado, Derecho y Políticas Públicas de la Universidad Santo Tomás Bucaramanga, y del Doctorado en Derecho de la Universidad Autónoma de Morelos México. 
Esta medición, además de clasificar a los países de acuerdo con el grado de seguridad, nos permite conocer grosso modo los principales motivos, y en México el principal motivo del incremento de la violencia es la estrategia de la contención de la violencia, creando y reclutando personal de seguridad, por lo que se ha convertido en uno de los motivos por los cuales sigue incrementando la problemática. Resulta claro que la estrategia de contención de la violencia, nunca va a disminuir la violencia, pues esta no representa una solución de fondo.

Por otra parte, la Oficina del Alto Comisionado de las Naciones Unidas, denunció en el mes de marzo de 2015 que en México se vive una crisis en materia de derechos humanos, situando al país en una lista de 30 países que mayormente violan los derechos humanos de sus ciudadanos, mostrando su preocupación y señalando que

Mexico is a stark example of the way unchecked criminal violence can threaten hard-won democratic gains. I have repeatedly expressed my concern over generalised violence in parts of Central America and in Mexico, and alleged links between organised crime, security forces and local and central authorities. The disappearance of 43 students in Iguala is far from an isolated case, but it challenges the authorities to take decisive action to end impunity and prevent such crimes in the future (Rights, 2015).

Es claro que la violencia e impunidad son fenómenos que han impactado en la paz de millones de personas que se encuentran en el país, pues vivimos en un constante conflicto, del cual parece no tener solución en el corto plazo, pues para que la paz prospere se requiere de una cimentación profunda y sólida, en la que participen los gobiernos, la sociedad y la comunidad internacional en general, pues no hay duda que la construcción de la paz es el requisito previo para el desarrollo económico, social y democrático de los pueblos.

Es por ello que, para entender los retos que tiene México en el contexto actual y plantear las posibles soluciones al problema de la paz y los derechos humanos en México, es necesario conocer ese contexto, entender: cuáles son las características específicas que imperan en el país, cuáles son los indicadores y el panorama actual, para conocer a fondo esta crisis expondremos de manera breve dicha situación.

\section{Metodología}

En este artículo se utilizan dos perspectivas metodológicas: la analítica y comparativa. La perspectiva analítica permite buscar, analizar y descomponer todos los conceptos y definiciones de los temas que se pretenden abarcar, aclarar los conceptos, sus alcances y límites desde un punto de vista crítico y propositivo. Con la perspectiva comparativa se buscará analizar sistemáticamente la finalidad de la verificación de la hipótesis. 


\section{CONTEXTO NACIONAL, MÉXICO EN UNA CRISIS GENERAL DE VIOLENCIA, INSEGURIDAD, JUSTICIA Y CORRUPCIÓN}

Es indudable que la sombra de la inseguridad y violencia ha estado presente en el país desde hace varias décadas, pero desde hace más de nueve años se sufre una severa y profunda crisis de inseguridad, violencia, impunidad y corrupción, la cual ha impactado en el deterioro de los derechos humanos, una crisis a la que el propio Estado no encuentra solución y que por lo contrario es parte de ella.

También es necesario señalar que en México el imperio de la ley se encuentra corrompido, es decir, quien tiene los medios para hacer caminar la justicia puede acceder de manera pronta y expedita a ella, de allí deviene la impunidad tan lastimosa que se vive; por otra parte, nuestras instituciones se encontraban desmanteladas, y en muchos casos ocupadas por la delincuencia organizada, motivos por los cuales existe una desconfianza en estas, ya lo dijo Zygmun Bauman que "las personas tienden a vivir en paz y a abstenerse de emplear la violencia cuando pueden dirigir sus quejas y sus rencillas a un poder en cuya incorruptibilidad e imparcialidad pueden confiar" (Bauman, 2010) es por ello que si contamos con instituciones que se desmoronan y que no tienen credibilidad, se fomenta la violencia y se da un duro golpe a la cultura de la paz y a los derechos humanos.

Desde que comenzó la lucha contra las organizaciones delincuenciales cuya principal actividad es la producción, el trasiego y distribución de droga en el país, se han registrado y documentado innumerables violaciones a los derechos humanos, como lo son casos de tortura, privación de la libertad, desapariciones forzadas de personas, desplazados, así como la ejecución de miles de individuos; actos que sin lugar a dudas son degradantes de la dignidad humana, y ponen a México como uno de los países más violentos de Latinoamérica y del mundo (Holder, 2014).

Toda esta problemática y sus consecuencias, son síntomas de que el Estado mexicano, en algunas regiones del país fue verdaderamente omiso en la tutela de los bienes, libertades y los derechos de la población y las víctimas. Ello porque se ha perdido el Estado de derecho, como lo es el claro ejemplo de Guerrero, Michoacan y Tamaulipas, donde se apreció por mucho tiempo que no existe o es muy débil su estructura constitucional y con ello sus instituciones, ni mucho menos el conjunto de procedimientos tendientes a asegurar el respeto a los derechos fundamentales de los ciudadanos.

Ante esta situación, desde hace varios años, el gobierno de México ha manejado un discurso con doble moral en cuanto al tema de la seguridad, así como del respeto, protección y defensa de los derechos humanos, presentándose incluso a nivel internacional con una imagen renovada y de nuevos aires en la materia, pero si hacemos una comparativa con la realidad que existe en materia de seguridad y respeto de derechos humanos en el interior del país (Unidas N., 2013) podríamos calificarla de una gran simulación y una total y grave catástrofe. 
Problemática que ha afectado a miles de víctimas inocentes, como lo son civiles, empresarios, migrantes, periodistas, activistas en defensa de los derechos humanos, estudiantes, mujeres y niños (Watch, 2011), tal parece que de esta ola de violencia nadie se salva, millones de mexicanos se encuentran afectados y heridos al vivir una impunidad generalizada, lo que genera un clima de miedo y zozobra a las familias y comunidades.

Los números no mienten, de acuerdo con el Sistema Nacional de Seguridad Pública, en su reporte anual 2014, informa que el número de homicidios en ese año fue de treinta y seis mil (36 000) personas (Publica, 2015) que han perdido la vida, derivado de la violencia en el país, esta información surge de acuerdo con las denuncias y carpeta de investigación iniciadas en ese mismo año.

Cifra que sin duda nos muestra la magnitud de la tragedia en tan solo un año, pues esta lucha contra las drogas está por cumplir una década, la misma que ha dejado una marca en la historia de México, y que se considera una gran tragedia y una pesadilla para quienes habitan y transitan en este país.

Lamentablemente las cifras que manejan las instituciones gubernamentales son poco creíbles y muy discutibles, es lo que afirma la organización italiana denominada Libera, al señalar de manera directa una discrepancia significativa en los homicidios ocurridos en México del año 2006 al 2012, compara que el Instituto Nacional de Estadística y Geografía (INEGI) desde el 2005 al 19 de julio del 2012, establece 116005 "presuntos homicidios", pero de acuerdo con sus investigaciones empíricas metodológicas de Liberia, publicadas en el mes septiembre de 2012 por autores norteamericanos y canadienses "El uso, el mal uso y abuso de estadísticas de homicidios organizados"; en el estudio mencionado se calcula que el total de homicidios dolosos durante el sexenio 2006-2012 serán aproximadamente 136,100 (ciento treinta y seis mil) homicidios dolosos (Mafie 2012).

Por la cantidad de casos documentados por estas importantes organizaciones internacionales, se demuestra que México se encuentra en un conflicto grave, y que sin duda está falto de paz. Con independencia de que las autoridades traten de modificar la Información, se maquille, o sea escondida por los institutos y dependencias del gobierno mexicano, resulta por demás claro de la gravedad de la situación que impera en unas zonas del país, donde no se puede esconder la dimensión de esta pesadilla.

Pesadilla que no solo ha sido generada por miembros de la delincuencia organizada, sino que también ha participado la policía y las fuerzas de seguridad (International, 2013) las cuales han cometido, entre otros delitos, ejecuciones extrajudiciales, desapariciones forzadas y tortura.

\section{Desapariciones forzadas de persona}

En el caso de las desapariciones forzadas, la organización internacional Human Rights Watch, ha denunciado que en México existen más de 25000 desapariciones de personas en todo el país, mediante un informe ha documentado 250 casos, de los 
cuales ha denunciado que cerca de 140 de ellos, son desapariciones forzadas, en las cuales los sujetos activos son agentes de seguridad, es decir, han sido perpetradas por miembros de corporaciones como: la Marina, las policías locales, federales, ministeriales, Ejército y en ocasiones conjuntamente con la delincuencia (Watch, 2013).

Aquí es indispensable analizar qué entendemos por desaparición forzada de persona y las características que esta debe contener para ser considerada como tal, para así poder ser capaces de diferenciarla con la sola denominación de desaparición de personas, aclarando que no pretendemos hacer menos a una sobre la otra, pues el simple hecho de que miles de personas estén desaparecidas en el país, sea cual sea el modus operandi y las personas que participan, es una situación alarmante, que merece todos los esfuerzos para resolverse.

En ese sentido, de acuerdo con el artículo II de la Convención Interamericana sobre Desaparición Forzada de Personas, se considera desaparición forzada a la privación de la libertad a una o más personas, cualquiera que fuere su forma, cometida por agentes del Estado o por personas o grupos de personas que actúen con la autorización, el apoyo o la aquiescencia del Estado, seguida de la falta de información o de la negativa a reconocer dicha privación de libertad o de informar sobre el paradero de la persona, con lo cual se impide el ejercicio de los recursos legales y de las garantías procesales pertinentes (Americanos, Convención Interamericana sobre Desaparición Forzada de Personas, 1994)

Mientras que la Convención Internacional para la protección de todas las personas contra las desapariciones forzadas, define en su artículo segundo que:

se entenderá por «desaparición forzada» el arresto, la detención, el secuestro o cualquier otra forma de privación de libertad que sean obra de agentes del Estado o por personas o grupos de personas que actúan con la autorización, el apoyo o la aquiescencia del Estado, seguida de la negativa a reconocer dicha privación de libertad o del ocultamiento de la suerte o el paradero de la persona desaparecida, sustrayéndola a la protección de la ley (Humanos, 2006).

De acuerdo con estas definiciones del delito de desaparición forzada de persona, podemos afirmar que esta guarda como elementos concurrentes y constitutivos para su encuadramiento: a) la privación de la libertad; b) la intervención directa de agentes estatales o la aquiescencia de estos; c) la negativa de reconocer la detención y de revelar la suerte o el paradero de la persona interesada, y d) la sustracción de las personas a la protección de la ley.

Afirmamos categóricamente que en México en la mayoría de las más de 25000 desapariciones guardan los elementos antes señalados, ello nos indica que se está haciendo una práctica generalizada o sistemática de este delito.

Es importante señalar que, la participación de fuerzas de seguridad en la comisión de delitos, como lo es la desaparición forzada de personas, nos indica que en México se está perdiendo el Estado de derecho, el cual se entiende "como una estructura constitucional y un conjunto de procedimientos tendientes a asegurar el respeto a los 
derechos fundamentales de los ciudadanos y a evitar los abusos del poder" (Carranza, 2002) Al existir participación de cuerpos de seguridad en la comisión de delitos, es evidente que estamos ante el abuso del poder en contra de la población mexicana.

Es preciso no olvidar que, las desapariciones forzadas en México no son un caso aislado, motivo por el cual el país se encuentra por primera vez en examen ante el Comité contra la Desaparición Forzada, que es el encargado de supervisar el cumplimiento de la Convención Internacional para la protección de todas las personas contra las desapariciones forzadas, y cuyas observaciones finales se dieron a conocer en la sesión celebrada el 11 de febrero de 2015.

De las conclusiones de esta revisión, el Comité confirma que existe un contexto de desapariciones generalizadas en gran parte del territorio del Estado mexicano, muchas de las cuales podrían calificarse como desapariciones forzadas, incluso iniciadas a partir de la entrada en vigor de la Convención (Forzada, 2015).

Al vivir en un contexto generalizado de esta práctica en México, es por demás claro que, la desaparición forzada constituye en un delito de lesa humanidad, ello en virtud de que se está haciendo una práctica generalizada o sistemática de este delito, pues en gran parte del territorio se vive una crisis generada por los propios gobiernos (Humanos, Convención Internacional para la protección de todas las personas contra las desapariciones forzadas, 2006), la cual ha dejado más de 25000 casos de personas desaparecidas, que en su gran mayoría se puede configurar el tipo penal de desaparición forzada.

Delitos de lesa humanidad que deben ser investigados y sancionados, pues así lo ha sostenido la Asamblea General de las Naciones Unidas en su resolución 3074 XXVIII de 1973:

...dondequiera y cualquiera que sea la fecha en que se hayan cometido, serán objeto de una investigación, y las personas contra las que existan pruebas de culpabilidad en la comisión de tales crímenes serán buscadas, detenidas, enjuiciadas $\mathrm{y}$, en caso de ser declaradas culpables, castigadas (Unidas, 1973).

Es claro que al realizarse la investigación, enjuiciamiento y castigo de los responsables de aquellos que cometieron los delitos de lesa humanidad, se está evitando que dichos eventos se repliquen, siendo una de las mejores formas de prevenirlos, esto lo encontramos previsto en la Resolución 2583 (XXIV) de 1969 de la Asamblea General de las Naciones Unidas, que a la letra reza:

... la «investigación rigurosa» de los crímenes de guerra y los crímenes de lesa humanidad, así como la sanción de sus responsables, «son un elemento importante para prevenir esos crímenes y proteger los derechos humanos y las libertades fundamentales, y para fomentar la confianza, estimular la cooperación entre pueblos y contribuir a la paz y la seguridad internacionales (Unidas, 1969). 
Al ser la desaparición forzada en México un delito de lesa humanidad, existe una inexcusable obligación internacional de llevar ante la justicia a los responsables de estos crímenes contra la humanidad como en el caso Ayotzinapa y en los más de 25000 casos de desapariciones, obligación que surge del marco jurídico interno, pues de acuerdo con la reforma a la Constitución en materia de derechos humanos de fecha 10 de junio de 2011, se impone la obligación de que todas las autoridades del Estado adopten medidas capaces de garantizar la observancia del pluralismo jurídico internacional de derechos humanos, ello en atención al principio pro persona y pro dignitate.

\section{Ejecuciones extrajudiciales, sumarias o arbitrarias}

En México, tal y como lo señalábamos anteriormente, se vive bajo violaciones graves al derecho a la vida, en el contexto esta situación se agrava cuando las personas encargadas de brindar seguridad y protección son quienes cometen las ejecuciones. Ejemplo de estos actos son los hechos ocurridos en Acteal y El Bosque, en el estado de Chiapas, y en El Charco y Aguas Blancas, en el estado de Guerrero. Dentro de los casos más recientes de inicio de este siglo son los ocurridos en Tlatlaya en el estado de México y el de Apatzingán en el estado de Michoacán, acontecimientos que han dejado de ser hechos aislados, sino todo lo contrario, son crímenes que se perpetran con mucha frecuencia en el país, y donde se encuentra documentado y probado que existe un uso excesivo e indiscriminado de la fuerza, que ha acabado con la vida de civiles inocentes.

Estos casos que se mencionan, son tan solo una muestra de los problemas profundamente arraigados en el país, los cuales además, son el ejemplo de la impunidad de los infractores de los derechos humanos a la vida, a la integridad personal y a la libertad; representan la total ineficacia del sistema judicial y una falta que afecta al país y a toda su población, pues lejos de salvaguardar los derechos humanos, son quienes atentan contra ellos.

De acuerdo con el relator de las Naciones Unidas Christof Heyns, al presentar el Informe Especial sobre las ejecuciones extrajudiciales, sumarias o arbitrarias, documenta y presenta al Gobierno de México 31 casos concretos en que al parecer se había vulnerado el derecho a la vida, los cuales se habían producido entre 2007 y 2012.

Heyns sostiene que las principales violaciones denunciadas figuraban, a veces combinadas, las siguientes: amenazas de muerte; muerte de personas detenidas; muertes a manos de miembros del Ejército, la Marina y la Policía; uso excesivo de la fuerza por agentes de las fuerzas del orden; muertes durante manifestaciones de protesta; muertes a manos de supuestos miembros de grupos armados ilegales; y desapariciones forzadas, torturas y detenciones arbitrarias causantes de muerte (Unidas, A. G., 2014) 
Ante los actos descritos por el relator de las Naciones Unidas, además de los casos más recientes y de mayor divulgación internacional como es el caso Tlatlaya en el cual el Ejército asesinó a 22 personas sin el respeto mínimo de sus derechos humanos y la observancia de sus garantías judiciales; o el caso de Apatzingán, en el que fuerzas federales masacraron a 16 ciudadanos al momento del desalojo del palacio municipal, empleando para ello el uso brutal y excesivo de la fuerza.

Es claro que México tiene un gran desafío para hacer que se respete el derecho a la vida, pues este es un derecho protegido por diversos instrumentos internacionales de derechos humanos, como lo es el Pacto San José:

Artículo 4. Derecho a la Vida

1) Toda persona tiene derecho a que se respete su vida. Este derecho estará protegido por la ley y, en general, a partir del momento de la concepción. Nadie puede ser privado de la vida arbitrariamente (Americanos, Convención Americana sobre Derechos Humanos (Pacto de San José), 1969).

De esta importante convención, se desprende que ninguna persona puede ser privada de la vida de manera arbitraria, para ello, el Estado debe garantizar las condiciones y la legislación necesaria para poder salvaguardar este importante derecho, el cual consideramos es el más valioso con el que cuenta la humanidad, ya que sin él, no somos nada; en este sentido ha sostenido en su jurisprudencia la Corte IDH que "el derecho a la vida tiene un papel fundamental en la Convención Americana por ser la condición previa para la realización de los demás derechos. $\mathrm{Al}$ no ser respetado el derecho a la vida, todos los derechos carecen de sentido" (Caso Myrna Mack Chang Vs. Guatemala. Fondo, Reparaciones y Costas, 2003).

Si no contamos con el pre requisito "la vida", no podemos siquiera pensar en la titularidad de derechos y obligaciones, pues para gozar de ellos se requiere de la existencia misma de la persona, de allí que sea el derecho más importante que tiene el hombre.

Lamentablemente, las fuerzas de seguridad al privar de la vida a personas inocentes en sus operativos, es una clara señal de que existe un enorme desconocimiento por parte de los elementos y fuerzas de seguridad sobre este importante derecho, o quizá no tienen la conciencia mínima de este.

Aquí es importante señalar que de acuerdo con Relator Especial sobre ejecuciones extrajudiciales, sumarias o arbitrarias, Christof Heyns:

la violación del derecho a la vida se produce tanto por la privación de la vida por parte de actores estatales, tales como las fuerzas del orden, cuanto por la incapacidad del Estado para ejercer la debida diligencia para prevenir muertes a manos de agentes no estatales. También se produce por la falta de investigación adecuada, de identificación correcta, de rendición de cuentas de los responsables y de reparación de las víctimas (2013).

Aquí el Estado mexicano ha mostrado su incapacidad de prevenir las muertes de civiles a manos de las fuerzas de seguridad, esto se debe a que los elementos carecen 
de una amplia formación en materia de respeto de los derechos humanos, es por ello que los responsables del cumplimiento de la ley, deben recibir una formación sólida en materia de respeto de los derechos fundamentales de las personas sometidas a su control; así mismo, tal y como lo señala el relator de Naciones Unidas, las investigaciones de estos crímenes han sido deficientes, permitiendo que exista una impunidad en los casos de ejecuciones extrajudiciales.

En cuanto al tema de las investigaciones, de acuerdo con la Corte Interamericana de Derechos Humanos:

en casos de ejecuciones extrajudiciales... el Tribunal ha considerado que la realización de una investigación ex officio, sin dilación, seria, imparcial y efectiva, es un elemento fundamental y condicionante para la protección de ciertos derechos que se ven afectados o anulados por esas situaciones, como los derechos a la libertad personal, integridad personal y vida (Caso Heliodoro Portugal Vs. Panamá". Excepciones Preliminares, Fondo, Reparaciones y Costas. Sentencia, 2008).

Lamentablemente esto no sucede, y mucho menos cuando se encuentran vinculados miembros del Ejército, la Marina, las policías locales y federales.

Las investigaciones en los casos de ejecuciones extrajudiciales no cuentan con una seriedad suficiente; son parciales, ejemplo de ello es la justicia castrense, la cual ha sido señalada por no ser independiente e imparcial, la cual la hace menos efectiva. Todo ello trae consecuencias graves como lo es la impunidad, la cual está generando una cultura dentro de las instancias de procuración, investigación y sanción de estos delitos.

Aquí juega un papel importante la investigación, para ello se debe de cumplir plenamente con el Model protocol for a legal investigation of extra-legal, arbitrary and summary executions, o también llamado protocolo de Minnesota, el cual prevé los principios rectores que se deben de observar cuando se considera que una muerte pudo deberse a una ejecución extrajudicial. A saber son los siguientes:

a) To identify the victim;

b) To recover and preserve evidentiary material related to the death to aid in any potential prosecution of those responsible;

c) To identify possible witnesses and obtain statements from them concerning the death;

d) To determine the cause, manner, location and time of death, as well as any pattern or practice that may have brought about the death;

e) To distinguish between natural death, accidental death, suicide an (homicide);

f) To identify and apprehend the person(s) involved in the death;

g) To bring the suspected perpetrator(s) before a competent court established by law (Nations, 1991). 
Principios rectores que deben conducir la investigación, ya que sin ellos, es casi improbable de manera científica dar con los responsables de aquellas autoridades que cometen actos de ejecución extrajudicial, y mucho menos, poder llegar al conocimiento de la verdad del que tantas víctimas indirectas reclaman en el país.

En relación con ello, la Corte IDH ha elaborado constructos teóricos, señalando que el derecho a la verdad se encuentra subsumido en el derecho de la víctima o sus familiares a obtener de los órganos competentes del Estado el esclarecimiento de los hechos violatorios y las responsabilidades correspondientes, a través de la investigación y el juzgamiento que previenen los artículos 8 y 25 de la Convención (Caso Bámaca Velásquez Vs. Guatemala, 2000).

Además de contar con una investigación adecuada y eficaz, y al estar el derecho humano a la vida gravemente amenazado en México, las Naciones Unidas han manifestado que es imperativo disminuir la participación del ejército en las actividades policiales; velar por que los militares acusados de haber cometido violaciones de los derechos humanos sean enjuiciados por tribunales civiles y no militares; y establecer normas claras y ampliamente difundidas sobre el uso de la fuerza por los agentes de las fuerzas del orden en todos los niveles de gobierno (Unidas A. G., 1969, p. 2).

Pues el Ejército al realizar labores de seguridad se ha convertido en una de las instituciones a nivel nacional que mayormente viola los derechos humanos, esto de acuerdo con los números de recomendaciones que ha emitido la $\mathrm{CNDH}$, por lo que es urgente que las fuerzas militares salgan de las calles, pues no se puede combatir la delincuencia, ni mucho menos aplicar la ley, si para ello se emplea la violación a los derechos humanos.

\section{Tortura, tratos crueles, inhumanos o degradantes}

Diversas organizaciones internacionales de protección de derechos humanos han señalado de manera directa a México como un país en donde la práctica de la tortura es generalizada, la cual ocurre muy frecuentemente desde que las personas son detenidas, e inclusive cuando se ponen a disposición de la justicia, pues diversas fuerzas policiales y militares emplean esta con la finalidad de generar castigo, como el medio para profundizar sus investigaciones o simplemente para intimidar a los detenidos.

Al realizar toda clase de tratos crueles, inhumanos o degradantes, se viola de manera directa el artículo 20 de la Constitución Política de los Estados Unidos Mexicanos, mismo que prohíbe y sancionará toda incomunicación, intimidación o tortura.

Para entender a fondo la tortura en México, la Convención Interamericana para Prevenir y Sancionar la Tortura define a esta como:

todo acto realizado intencionalmente por el cual se inflijan a una persona penas o sufrimientos físicos o mentales, con fines de investigación criminal, como medio intimidatorio, como castigo personal, como medida preventiva, 
como pena o con cualquier otro fin. Se entenderá también como tortura la aplicación sobre una persona de métodos tendientes a anular la personalidad de la víctima o a disminuir su capacidad física o mental, aunque no causen dolor físico o angustia psíquica (Americanos, Convención Interamericana para Prevenir y Sancionar la Tortura, 1987).

De acuerdo con esta definición, tenemos que la tortura tiene como fin el anular la personalidad de las víctimas, pues se emplean métodos y castigos que degradan la dignidad humana, causando afectaciones físicas o psíquicas a quienes resienten este delito.

De esa definición podemos sustraer que los elementos que constituyen el delito de tortura son los siguientes: I) un acto realizado intencionalmente; II) que se cometa con determinado fin o propósito determinado, y III) que anule la personalidad de la víctima o que cause sufrimientos físicos o psíquicos.

Es importante conocer quiénes pueden ser responsables de este delito, en ese sentido y de acuerdo con la ley federal para prevenir y sancionar la tortura, en su artículo $3^{\circ}$, se señala que:

comete el delito de tortura el servidor público que, con motivo de sus atribuciones, inflija a una persona dolores o sufrimientos graves, sean físicos o psíquicos con el fin de obtener, del torturado o de un tercero, información o una confesión, o castigarla por un acto que haya cometido o se sospeche ha cometido, o coaccionarla para que realice o deje de realizar una conducta determinada (Unión, 1991).

Consideramos que dicha responsabilidad es muy limitada, es decir, en esta legislación únicamente pueden ser responsables los servidores públicos, motivo por el cual no está en armonía con la Convención Interamericana para Prevenir y Sancionar la Tortura, pues, de esta última se advierte en su artículo $3^{\circ}$ que pueden ser responsables tanto los funcionarios públicos como cualquier persona que sea cómplice o participe de manera directa en la tortura.

Motivo por el cual muchas personas que cometen tortura en México y que no tienen el carácter de servidor público se pueden sustraer de la acción de la justicia, trayendo como consecuencia impunidad en los delitos de tortura de persona. Por ello se insiste que es necesario ajustar a los responsables de la comisión de tortura de acuerdo con lo que establecen los lineamientos internacionales y regionales.

La gravedad del problema ha sido consistentemente denunciada, pues la tortura es una práctica común por las autoridades de prevención e investigación de los delitos, además que a últimas fechas, esta presenta un alarmante incremento en su práctica, señala Amnistía Internacional que:

la tortura y otros malos tratos aumentaron a partir de 2006, a partir de la violencia como consecuencia de la «guerra contra las drogas», así mismo, denuncia esta importante organización que en 2013 hubo un 600 por ciento más de denuncias respecto de 2003 (Internacional, 2014). 
De acuerdo con estas cifras, podemos asegurar que cualquier persona que esté bajo detención en el país por las fuerzas militares y policiales, corre un riesgo potencial de sufrir tortura.

Para dar una idea clara de la problemática, La Comisión Nacional de los Derechos Humanos ha registrado un aumento en las quejas por la comisión del delito de tortura desde 2007, y reportó más de 2020 quejas en 2011 y 2113 en 2012, comparadas con un promedio de 320 en los seis años anteriores a 2007. Entre diciembre de 2012 y julio de 2014, la CNDH recibió 1148 quejas por violaciones atribuibles solo a las fuerzas armadas (Méndez, 2014).

Lo señalado por la CNDH nos dice que las corporaciones policiacas y militares no están respetando el derecho de un trato digno y humano de las personas sujetas a detención; vulneran el derecho a la legalidad y seguridad jurídica de las personas, se pone en peligro el derecho a la salud y a la integridad personal.

Hay un incremento en el número de quejas, así como una certeza mayor de que cada día más somos potencialmente víctimas de tortura, derivado del incremento de elementos policiacos y militares en las calles, se estima que en el 2012 había alrededor de 50000 efectivos policiales, mientas que la militarización ascendió a 32000 efectivos (Méndez, 2014).

Lejos de ser un motivo de seguridad el que más elementos policiacos y militares estén en las calles, es un motivo de preocupación, pues su actuar es a todas luces contrario a los derechos humanos contenidos en la Constitución mexicana y en diversos tratados internacionales.

Amnistía Internacional, por más de 50 años ha denunciado que los métodos de tortura y otros malos tratos más habituales en México, son:

- Golpes con puños, botas, culatas de fusiles, palos;

- Introducción de agua con gas o chile por la nariz del detenido;

- Amenazas de muerte;

- Descargas eléctricas en partes del cuerpo como los dedos de los pies y los testículos;

- Simulacros de ejecución y amenazas de desaparición forzada;

- Semi-asfixia mediante bolsas de plástico o trapos mojados, y simulacros de ahogamiento;

- Posturas en tensión;

- Violación y otras formas de violencia sexual;

- Amenazas contra las familias de los detenidos (Internacional, 2014, pp. 11-12).

Ante los actos inhumanos y degradantes, el Estado mexicano no muestra preocupación por el actuar de sus corporaciones policiacas y militares en las detenciones e investigaciones, incluso este ha descalificado y minimizado los casos de tortura, de tratos inhumanos y degradantes. Demeritando las investigaciones y denuncias que hacen los organismos internacionales y sus relatores. 
Las autoridades mexicanas niegan el uso generalizado de la tortura, por este motivo no adoptan las medidas ni recomendaciones que devienen del plano internacional, ni mucho menos inician una investigación inmediata, seria e imparcial para sancionar los abusos de los cuerpos de seguridad.

Todo ello es contrario a lo establecido por la Convención Interamericana para Prevenir y Sancionar la Tortura, la cual señala en su artículo $8^{\circ}$ que:

una vez que exista denuncia o razón fundada para creer que se ha cometido un acto de tortura en el ámbito de su jurisdicción, los Estados partes garantizarán que sus respectivas autoridades procederán de oficio y de inmediato a realizar una investigación sobre el caso y a iniciar, cuando corresponda, el respectivo proceso penal (Americanos, Convención Interamericana para Prevenir y Sancionar la Tortura, 1987).

Es claro que al no investigar de oficio los casos de tortura, al no existir independencia e imparcialidad en las investigaciones, y que estas tengan una demora injustificada, trae como consecuencia que no se sancionen a los responsables, y que muchos casos de tortura queden totalmente impunes. Todo ello ocasiona que en México exista "una situación generalizada del uso de tortura y malos tratos" (Méndez, 2014, p. 1).

\section{Corrupción e impunidad, el cáncer de México}

La corrupción ha sido definida de diferentes maneras, una de las más comunes, populares y acertadas es la que aplica muy frecuentemente el International Monetary Fund (IMF), el cual señala que: "corruption is the abuse of public power for private benefit" (Fund, 1998), es precisamente utilizar una ventaja de poder, para sacar un provecho. En México generalmente las autoridades se aprovechan de la pobreza, o incluso los particulares la ven como el medio más rápido para salir de esta.

Es por ello que uno de los graves problemas en el país que dan lugar a la corrupción, es la pobreza, que de acuerdo con las cifras del CONEVAL en el 2012 la población pobre en el país era de 53.3 millones de personas, mientras que en ese mismo año 11.5 millones de personas vivían y continúan viviendo en extrema pobreza (Social, 2012).

Es la corrupción la que ha permitido que las bandas criminales se inserten en el Gobierno, en las policías, y es como lo dicen muchos autores el mejor engrane para que nuestro sistema justicia pueda caminar, es decir, tenemos una corrupción institucionalizada. La cual es la más grave de las corrupciones, de acuerdo con la APEC, esta se clasifica en dos tipos:

spontaneous and institutionalized (or systemic). Spontaneous corruption is usually found in societies observing strong ethics and morals in public service. Institutionalized corruption, on the other hand, is found in societies where corrupt behaviors are perennially extensive or pervasive. In these societies, corruption has become a way of life, a goal, and an outlook towards public office (Coperation, 2006). 
Desde nuestra óptica, cualquier tipo de corrupción es grave, pues la corrupción espontánea lleva a la corrupción institucionalizada, lo que si hay que dejar en claro que el tener una corrupción institucionalizada es una problemática social, pues es esta una forma de vida, y se aceptan como actos generalizados y continuos de la sociedad. Es decir, es una corrupción muy avanzada y arraigada.

La corrupción institucionalizada es uno de los problemas más graves y arraigados en el país, pues de acuerdo con el Índice de Percepción de la Corrupción 2014, que emite la Organización Transparencia Internacional, se arrojó que de los 34 países que integran la OCDE, México es uno de los países con la peor puntuación (International, 2014), es decir, vivimos en un país con altos niveles de corrupción, donde no impera la legislación, sino la ley del poder económico y los intereses privados.

La práctica de la corrupción ha sido la puerta para que la delincuencia y el dinero del crimen se incrusten en la política, mediante el financiamiento de las campañas y candidatos, como lo fue en el caso de Iguala Guerrero con lo de los 43 normalistas desaparecidos, o en muchos otros municipios del país como es el caso de Michoacán.

La corrupción es la puerta para que las corporaciones de seguridad, policiales y militares no cuiden a la ciudadanía, sino todo lo contrario protejan sus propios intereses, y de aquellos que pagan mejor.

La corrupción significa además la llave de las prisiones, en este país quien cuenta con los medios suficientes para sobornar a los jueces, fiscales y policías, nunca pisará una prisión, ni mucho menos recibirá un castigo. Es claro que la corrupción deviene en otro problema en México, este es precisamente la impunidad.

Señala la Corte IDH que la impunidad es "la falta en su conjunto de investigación, persecución, captura, enjuiciamiento y condena de los responsables de las violaciones de los derechos protegidos por la Convención Americana" (Caso Huilca Tecse Vs. Perú. Fondo, Reparaciones y Costas, 2005)

Pues el incumplimiento de la investigación, procesamiento y sanción de todos aquellos que comente violaciones graves a los derechos humanos, como es el caso de desaparición forzada, privación de la vida y violación a la integridad personal, es claro que se traduce en la repetición constante de esas violaciones de derechos humanos.

Impunidad que se refleja en la vida cotidiana y se representa claramente en las estadísticas, pues el Índice Global de la Impunidad (IGI) considera a México como el segundo país más impune del planeta, solo detrás de Filipinas.

De acuerdo con el IGI, México tiene dos dimensiones prioritarias que debe atender: la funcionalidad de su sistema de seguridad y la estructura de su sistema de justicia (Le Clercq, 2015). Admitiendo que no es necesario ya incrementar el número de policías en el país, pero sí indispensable incrementar el número de juzgadores, pues solo se cuenta con un promedio de 4 jueces por cada 100 mil habitantes.

El actuar del Gobierno y los particulares va en contra de la responsabilidad moral, la cual señala Zygmun Bauman es "la más personal e inalienable de las posesiones 
humanas, y el más preciado de los derechos humanos. Señalando el autor que esta no puede ser arrancada, compartida, cedida, empeñada, depositada en custodia" (Bauman, 2005).

Responsabilidad que tenemos todas las personas para aliviar los efectos tan devastadores de la violencia, que pareciera incontrolable, pero que cada día es más grave y afecta a muchas más personas.

Lejos de promover una cultura de responsabilidad moral, de los derechos humanos y la paz, los gobiernos se han empecinado en contener la violencia con mucha más violencia, tal y como lo asegura el Institute for Economics and Peace, la violencia ha tenido una escala mayor, ya que los últimos gobiernos mexicanos han apostado por la estrategia de la militarización y el empleo de más elementos policiales en las calles, lo que sin duda es un gran error, el cual se nota con el incremento de víctimas de tortura, desaparición forzada o que lamentablemente han perdido la vida a manos del Gobierno.

Lo más grave es, que en la mayoría de los casos no existen investigaciones prontas y efectivas, tendientes a procesar y sancionar a los culpables de la comisión de estos delitos, lo que sin duda, genera mayor desconfianza en las autoridades investigadoras y judiciales, y nos ha llevado a ser uno de los países en el mundo donde la impunidad es la característica más común en las violaciones graves a los derechos humanos.

La estrategia del uso de la fuerza ha fallado, por ello consideramos que se deben buscar otros caminos, y por ende consideramos que la estrategia más adecuada que las autoridades del gobierno mexicano deben emplear, es la que se refiere a la cultura de la paz y de los derechos humanos, la cual ha quedado relegada y olvidada.

Con esta estrategia se estarían observando las obligaciones generales de respeto y garantía que impone la $\mathrm{CADH}$, las cuales se tratan de un hacer especial y un no hacer, pues en México, las violaciones a los derechos humanos devienen de las acciones u omisiones del Estado Mexicano. A continuación se explicaran de manera muy general este tipo de obligaciones.

\section{Obligaciones de respeto y garantía de los derechos humanos}

De la Convención Americana de Derechos Humanos nacen dos importantes obligaciones generales para los Estados parte de la citada Convención, entre los que se incluye a nuestro país, los cuales son fundamentales para poder cumplir con los derechos y libertades de las personas que se consagran en este instrumento, estas son las obligaciones de respeto y de garantía.

\section{Obligación de respeto}

La obligación de respeto, de acuerdo con Ariel Rojas Caballero, es aquella que contraen los Estados para el efecto de no violar por acción u omisión alguno de los derechos reconocidos en las convenciones de derechos humanos (Caballero, 2012). 
La Corte Interamericana ha hecho reflexiones de esta obligación desde la primera de sus jurisprudencias que emitió el 29 de julio de 1988, y que nos dice lo siguiente:

165. La primera obligación asumida por los Estados Partes, en términos del citado artículo el 1.1 del Pacto de San José, es la de respetar los derechos y libertades reconocidos en la convención... (Caso Velásquez Rodríguez Vs. Honduras, 1988).

La obligación de respeto no solo se cumple con abstenerse de violar por acción $u$ omisión un derecho humano, tal y como lo afirma Ariel Alberto, si no que respetar impone una conducta gubernamental encaminada a cumplir el mandato internacional de naturaleza convencional, obligación que de acuerdo con Claudio Nash: "los Estados deben realizar las acciones de cumplimiento, que pueden ser tanto positivas, que (implican una actividad de prestación) o negativas que (implican una actividad de abstención)" (Rojas, 2009).

\section{Obligación de garantía}

En cuanto a la obligación de Garantía, se hace referencia a aquella conducta gubernamental positiva, que implica la acción de todo el aparato Estatal, para que dentro de su jurisdicción se propicien las condiciones que permitan a todas las personas, sin distinción, y de manera libre hacer realmente efectivo los derechos humanos consagrados en la convención, esta obligación se describe claramente en la jurisprudencia que se está comentando:

166. ...implica el deber de los Estados Partes de organizar todo el aparato gubernamental y, en general, todas las estructuras a través de las cuales se manifiesta el ejercicio del poder público, de manera tal que sean capaces de asegurar jurídicamente el libre y pleno ejercicio de los derechos humanos... (Caso Velásquez Rodríguez Vs. Honduras, 1988).

De acuerdo con esta importante jurisprudencia, es todo el aparato gubernamental, en todas sus estructuras, a través de la cual se manifiesta el ejercicio del poder público, que en México son el Poder Legislativo, Poder Judicial y el Poder Ejecutivo en sus tres niveles de gobierno, llámese Federal, Estatal y Municipal, quienes tienen la obligación de llevar a cabo la ejecución y el pleno desarrollo de los derechos humanos.

En esta primera jurisprudencia, de manera contundente la Corte Interamericana establece que el deber de garantía implica cuatro obligaciones importantes para los Estados:

166. ...Como consecuencia de esta obligación los Estados deben prevenir, investigar y sancionar toda violación de los derechos reconocidos por la Convención y procurar, además, el restablecimiento, si es posible, del derecho conculcado $\mathrm{y}$, en su caso, la reparación de los daños producidos por la violación de los derechos humanos (Caso Velásquez Rodríguez Vs. Honduras, 1988). 
Como se podrá observar, la obligación de garantía no solo implica el organizar todo el aparato gubernamental y todas sus estructuras sin tener un rumbo fijo, sino que esa organización tiene una finalidad, es decir, esta va orientada a que los Estados realicen todos aquellos actos tendientes a prevenir, investigar, sancionar y reparar cualquier violación a los derechos humanos.

La prevención juega un rol importantísimo para el pleno desarrollo y vigencia de los derechos humanos, ya que en palabras de Claudio Nash Rojas "el establecimiento de un sistema internacional de derechos humanos busca la prevención de violaciones de derechos humanos" (Rojas, 2009, p. 26), en ese sentido se afirma que

El Estado que más cumple con el tema de los derechos humanos es aquel que realmente evita que las personas sufran atentados contra su dignidad, esto es la prevención; impedir a toda costa que autoridades y particulares transgredan los derechos humanos, tarea que es complicada para los Estados al determinar cuáles son las medidas que se deben adoptar, en este sentido, la Corte ha establecido en su jurisprudencia que el deber de prevención abarca todas aquellas medidas de carácter jurídico, político, administrativo y cultural que promuevan la salvaguarda de los derechos humanos (Caso Velásquez Rodríguez Vs. Honduras, 1988).

Es claro que las obligaciones contenidas dentro del artículo primero de la convención en el país no se cumplen, es decir, nos encontramos muy lejos de poder hacer una realidad el tema de los derechos humanos, al no existir un respeto por parte de las autoridades, ni mucho menos la garantía de estos, simplemente el Estado mexicano ha realizado una serie de acciones cosméticas desorganizadas, sin un fin, y sin un rumbo, evidentemente se ha mostrado una incapacidad y no se ha asumido realmente un serio compromiso internacional en materia de derechos humanos, solo se ha demostrado una lentitud e incluso una simulación en la materia, lo que lo hace incurrir en una clara violación y responsabilidad internacional al no observar tan importantes obligaciones.

De acuerdo con la jurisprudencia de la Corte Interamericana

es el Estado quien está en el deber jurídico de prevenir de manera razonable las violaciones de los derechos humanos, de desarrollar de manera seria y adecuada con los medios a su alcance las investigaciones en relación a las violaciones que se hayan cometido dentro de su jurisdicción, con la finalidad de poder identificar a los responsables, así como de imponerles las sanciones y de asegurar a la víctima una adecuada reparación, todo ello con el objeto de asegurar la no repetición de actos violatorios a los derechos humanos de las personas por parte de particulares como de autoridades (Caso Velásquez Rodríguez Vs. Honduras, 1988), pero esto, lamentablemente, de manera íntegra no se realiza.

Hasta aquí hemos visto que la población mexicana se encuentra cansada, defraudada, incluso frustrada de que en sus comunidades no se respete el mínimo 
de derechos, de que las autoridades obstaculicen e impidan el pleno goce de estos. La población esta fastidiada de que no exista una organización en las estructuras de gobierno; los individuos, lamentablemente, con el amargo en la saliva y con los puños endurecidos toman las armas para salvaguardar sus derechos, sus posesiones $\mathrm{y}$, fundamentalmente, proteger la vida de sus familias. Todo ello implica una grave infracción a la Convención Americana por parte del Estado mexicano, lo que acarrea una responsabilidad internacional por no tratar de manera adecuada las violaciones en los términos que establece la Convención.

\section{La cultura de la paz y los derechos humanos, la vía idónea para combatir la violencia}

De manera brillante Cabrera Dircio ha señalado que la cultura de la paz es aquella que vaya generando un orden, y este se vea reflejado en las aspiraciones del ser humano, tendientes a buscar un ambiente agradable para su subsistencia, donde se asuma responsablemente sus derechos, pero también sus obligaciones en la formación de un futuro donde el ciudadano sea el generador de una vida sin violencia para las generaciones futuras (Dircio, 2014).

Orden que nace desde y para la sociedad, de manera responsable, consiente de sus derechos y de sus obligaciones, esto es lo que se requiere en el país, que exista conciencia que todos los seres humanos tenemos derechos, cuáles son estos derechos, la manera de ejercerlos, defenderlos, pero sobre todo, sabedores de que tenemos también responsabilidad con los derechos de terceras personas.

En México, se requiere de hacer de la cultura de los derechos humanos la mejor arma para combatir la violencia, no podemos combatir la violencia, violando los derechos de las personas, pues ha quedado demostrado que este no es el camino idónea para generar la cultura de la paz, pues hemos sido espectadores y testigos de que esta estrategia es fallida y totalmente reprobable, pues su resultado es proliferar violencia y generar una conflictiva que daña profundamente el tejido social.

El tema de la cultura de los derechos humanos en México es preocupante, la mayoría de los mexicanos ni siquiera los conocen, por eso nos hacemos esta pregunta: ¿Qué sucede cuando los derechos humanos no se conocen por la población y las autoridades? La respuesta a esta pregunta es muy sencilla: No se hacen valer; lo que definitivamente nos traslada a la situación actual tan dolorosa que se vive en el país, nos remite a ese panorama desolador en el que nos encontramos, en el que todos los días somos potencialmente víctimas de violaciones graves a nuestros derechos humanos, tanto de autoridades, como de particulares; ello se debe a que existen mínimas y muy tardías acciones del Estado por fomentar la cultura de respeto, protección y promoción de estos en la sociedad mexicana. 
Afirmamos que existe una mínima cultura de derechos humanos, pues apenas se comienza a realizar acciones tendientes a fomentarlos desde la educación, pues la reforma a la Constitución ha llegado muy tarde, en fecha 10 de junio de 2011, misma que se contiene en el artículo $3^{\circ}$ :

La educación que imparta el Estado tenderá a desarrollar armónicamente, todas las facultades del ser humano y fomentará en él, a la vez, el amor a la patria, el respeto a los derechos humanos y la conciencia de la solidaridad internacional, en la independencia y en la justicia.

(Reformado mediante decreto publicado en el Diario Oficial de la Federación el 10 de junio de 2011).

Aquí es importante señalar que los procesos culturales no se logran con un plumazo del legislador, es por ello que, a más de cuatro años de reformada la Constitución en materia de educación de derechos humanos, no se ha percibido un cambio significativo del respeto a los mismos, ya que desde nuestra reflexión no se ha instrumentado de manera adecuada el artículo $3^{\circ}$ constitucional, pues las autoridades no se han preocupado por generar las condiciones que permitan la enseñanza en todos los niveles educativos del país.

En ese sentido Juan David Velázquez Monsalve de manera muy atinada ha hecho la siguiente afirmación "la constante violación de derechos humanos es una manifestación evidente de la falta de difusión de esas pretendidas convicciones generales...", coincidimos con el autor, pues una de las problemáticas de las violaciones a los derechos humanos en México ha sido el desconocimiento total de ellos, esto derivado de la poca o en ocasiones nula difusión de las ideas de los derechos humanos. Idea que se venía exigiendo a todas las naciones en el mundo desde el año de 1948 en el importante preámbulo de la Declaración Universal de los Derechos Humanos que a la letra reza:

Considerando que el desconocimiento y el menosprecio de los derechos humanos han originado actos de barbarie ultrajantes para la conciencia de la humanidad, y que se ha proclamado, como la aspiración más elevada del hombre, el advenimiento de un mundo en que los seres humanos, liberados del temor y de la miseria, disfruten de la libertad de palabra y de la libertad de creencias.

Ideas que el Estado mexicano abandonó más de 61 años, y que evidencian el abismo del retraso en el fomento de los derechos humanos; motivo por el cual se vive una crisis en el interior del país en la materia, al no llevar a cabo cambios a la Constitución e implementar políticas que permitieran un acceso a la información, formación y difusión de los derechos.

Conscientes de la proliferación de los conflictos y del incremento de la violencia en el mundo, el 6 de octubre de 1999 la Asamblea General de las Naciones Unidas, en su quincuagésimo tercer período de sesiones tuvo a bien emitir la Declaración y Programa de Acción sobre una Cultura de Paz. 
Esta declaración define a la cultura de paz como un conjunto de valores, actitudes, tradiciones, comportamientos y estilos de vida basados en:

a) El respeto a la vida, el fin de la violencia y la promoción y la práctica de la no violencia por medio de la educación, el diálogo y la cooperación;

b) El respeto pleno de los principios de soberanía, integridad territorial e independencia política de los Estados y de no injerencia en los asuntos que son esencialmente jurisdicción interna de los Estados, de conformidad con la Carta de las Naciones Unidas y el derecho internacional;

c) El respeto pleno y la promoción de todos los derechos humanos y las libertades fundamentales;

d) El compromiso con el arreglo pacífico de los conflictos;

e) Los esfuerzos para satisfacer las necesidades de desarrollo y protección del medio ambiente de las generaciones presentes y futuras;

f) El respeto y la promoción del derecho al desarrollo;

g) El respeto y el fomento de la igualdad de derechos y oportunidades de mujeres y hombres;

h) El respeto y el fomento del derecho de todas las personas a la libertad de expresión, opinión e información;

i) La adhesión a los principios de libertad, justicia, democracia, tolerancia, solidaridad, cooperación, pluralismo, diversidad cultural, diálogo y entendimiento a todos los niveles de la sociedad y entre las naciones (Unidas A. G., 1999).

Todos estos valores, actitudes, tradiciones, comportamientos y estilos de vida, sin duda deben estar presentes en todos los niveles educativos del país, en todas las escuelas de México, debe existir una fuerte carga en contenido en materia de derechos humanos. A esto debe estar dirigida la reforma en materia de derechos humanos, a la instrumentalización del artículo $3^{\circ}$ de la Constitución mexicana.

\section{CONCLUSIONES}

Es claro que la violencia en México es el síntoma del fracaso de la cultura de la paz y los derechos humanos, que la estrategia emprendida por los últimos dos gobiernos no ha dado resultados positivos, pues lejos de disminuir este tipo de violencia, la ha recrudecido, y quienes son sujetos activos en las violaciones son los elementos de seguridad "Marina, Ejercito, policías locales, estatales y federales, Policía Ministerial o Científica”.

Indudablemente, se tiene que tomar la decisión y cambiar de paradigma, esto es encaminar al país por el sendero de los derechos humanos y una cultura solida de la paz, para generar en la colectividad una actitud distinta, aquí nos refugiamos en la teoría actitudinal que señala Richard A. Posner (2011). La cual nos dice que 
para explicar la realidad es importante recurrir a identificar las preferencias que la sociedad proyecta.

Tal y como lo señalábamos en el presente trabajo, la sociedad mexicana y su gobierno proyectan preferencias hacia la violencia y el conflicto, en ese sentido, tenemos que echar mano de la teoría actitudinal para hacer una inclinación, y pasar de ese modelo de violencia, a un modelo de paz, de respeto a la vida, que incite al fin de la violencia, la educación, el diálogo, la cooperación, el respeto pleno y la promoción de todos los derechos humanos y las libertades fundamentales, el arreglo pacífico de los conflictos, el respeto y el fomento de la igualdad de derechos y oportunidades de mujeres y hombres, el respeto y el fomento del derecho de todas las personas a la libertad de expresión, opinión e información, pero que sobre todo, tal y como lo señala la ONU, inculque en las personas los valores de libertad, justicia, democracia, tolerancia, solidaridad, cooperación, pluralismo, diversidad cultural, diálogo y entendimiento a todos los niveles de la sociedad y entre las naciones.

Pero todo ello, no puede ser posible si no se aplica la teoría legalista, la cual Posner señala que "debería ser la aplicación del texto oficialmente promulgado lo que determine el resultado" (2011, p. 36). En México se reconocen con la reforma de 2011 los derechos humanos a nivel constitucional, en ese sentido, es esta importante reforma la que tiene que determinar el resultado que la sociedad desea, que es el cumplimiento de los artículos 1 y 3 de nuestra Constitución, su instrumentación apegada a lo ordenado por la misma. Esto es que se respeten, promuevan y fomenten los derechos humanos.

Por último, se tiene que echar mano de la teoría organizacional y la pragmática, la primera señala Richard A. Posner:

se construye a partir de la idea de que un agente y su mandante "a la que llamaremos sociedad y gobierno" tienen intereses divergentes. Mientras que la pragmática se refiere a que se intenta articular una estructura organizativa que minimice la divergencia (2011, p. 51).

Pues se requiere de la organización de todas las autoridades del poder Ejecutivo, Legislativo, Judicial en conjunto con la sociedad civil, son indispensables para acabar con este fenómeno que afecta a miles de personas.

Debe existir una unión, y un engranaje entre sociedad y gobierno, con una organización mutua, que permita echar en práctica las recomendaciones de las organizaciones internacionales gubernamentales o independientes en materia de derechos humanos, que realmente tienda a cumplir lo señalado por la Constitución y tratados internacionales, pero que sobre todo, atienda los reclamos de las víctimas y la sociedad en su conjunto.

Solo así, renunciando a combatir la violencia con el empleo de la violencia, y reconociendo que se requiere atender de manera integral esta problemática, podremos minimizarla, e inclusive eliminarla, de otro modo este hermoso país estará condenado a seguir siendo una tierra de muertes, desapariciones forzadas, tortura, ejecuciones extrajudiciales, corrupción e impunidad. 


\section{REFERENCIAS}

Americanos, O. d. (1969). Convención Americana sobre Derechos Humanos (Pacto de San José). Convención Americana sobre Derechos Humanos, 1. San José, Costa Rica, San José, Costa Rica: OEA.

Americanos, O. d. (1987). Convención Interamericana para Prevenir y Sancionar la Tortura, 1. Cartagena de Indias, Colombia: OEA.

Americanos, O. d. (8 de junio de 1994). Convención Interamericana sobre Desaparición Forzada de Personas. Recuperado el 4 de abril de 2015 de http:// www.oas.org/juridico/spanish/tratados/a-60.html

Americanos, O. d. (1994). Convención Interamericana sobre Desaparición Forzada de Personas, 1. Belém do Pará, Brasil, Belém do Pará, Brasil: Departamento de Derecho Internacional, OEA.

Bauman, Z. (2005). Ética posmoderma. México, D.F.: Siglo XXI.

Bauman, Z. (2010). Mundo-consumo, ética del individuo en la aldea global. Buenos Aires, Argentina: Paidós.

Caballero, A. A. (2012). Los derechos humanos en México. México, D.F.: Porrúa.

Carranza, S. A. (2002). Los desafíos de la seguridad pública en México. México., D.F.: UNAM.

Caso Bámaca Velásquez Vs. Guatemala, Serie C No. 70 (Corte IDH 25 de noviembre de 2000).

Caso Heliodoro Portugal Vs. Panamá". Excepciones Preliminares, Fondo, Reparaciones y Costas. Sentencia, Serie C No. 186 (Corte IDH 12 de agosto de 2008).

Caso Huilca Tecse Vs. Perú. Fondo, Reparaciones y Costas, Serie C No. 121 (3 de marzo de 2005).

Caso Myrna Mack Chang Vs. Guatemala. Fondo, Reparaciones y Costas, Serie C No. 101 (Corte IDH 25 de noviembre de 2003).

Caso Velásquez Rodríguez Vs. Honduras, Serie C No. 4 (Corte IDH 29 de julio de 1988).

Coperation, A.-P. E. (2006). Anti-corruption and governance: The Philippine experience. Ho Chi Minh City, Viet Nam: APEC.

Corruption, T. I.-T. (2014). Visualising corruption perceptions index 2014. Berlín, Alemania: Transparency International.

Dircio, J. C. (2014). Mediación penal y derechos humanos. México, D.F.: Coyoacán.

Forzada, C. C. (2015). Observaciones finales sobre el informe presentado por México en virtud del artículo 29, párrafo 1, de la Convención. Ginebra, Suiza: Naciones Unidas.

Fund, I. M. (1998). Corruption around the world: causes, consequences, scope and cures. Francia: Fiscal Affairs Department. 
Heyns, C. (2013). Observaciones preliminares sobre la visita oficial a México del Relator Especial sobre ejecuciones extrajudiciales, sumarias o arbitrarias. México, D.F.: Naciones Unidas.

Holder, F. (2014). Índice de seguridad regional países latinoamericanos-2014. México, D.F.: FTI Consulting, Forensic \& Litigation Consulting.

Humanos, O. d. (2006). Convención Internacional para la Protección de todas las Personas contra las Desapariciones Forzadas. 1. Ginebra, Suiza, Ginebra: Naciones Unidas.

International, A. (2013). México, aumento de las violaciones de los derechos humanos $y$ de la impunidad. México., D.F.: Amnesty International.

Internacional, A. (2014). Fuera de control, tortura y otros malos tratos en México. Madrid: Amnesty International.

International, T. (2014). Visualising corruption perceptions Index 2014. Berlín, Alemania: Transparency International.

Le Clercq, J. A. (2015). Índice Global de Impunidad IGI 2015. México: Centro de Estudios sobre Impunidad y Justicia CESIJ.

Mafie, L. A. (2012). México la guerra invisible. Historias, cifras y negocios de los carteles criminales y la impunidad de las mafias mexicanas. Roma, Italia: Libera, peace per il messico.

Méndez, J. E. (2014). Informe del Relator Especial sobre la tortura y otros tratos o penas crueles, inhumanos o degradantes. México, D.F.: ONU.

Naciones Unidas, O. d. (2006). Convención Internacional para la Protección de todas las Personas contra las Desapariciones Forzadas. ONU.

Nations, U. (1991). Manual on the effective prevention and investigation of extralegal, arbitrary and summary executions. 12. Minneapolis, USA: The Advocates for Human Rights.

Peace, I. f. (2014). Global Peace Index. Sydney, New York, and Oxford: IEP.

Posner, R. A. (2011). Cómo deciden los jueces. México, D.F.: Ubijus, Inacipe.

Publica, S. N. (2015). Informe de víctimas de homicidio, secuestro y extorsión 2014. México, D.F.: Centro Nacional de Información.

Rights, O. o. (2015). Opening Statement, Item 2, High Commissioner's Annual Report. New York: United Nations.

Rojas, C. N. (2009). El sistema interamericano de derechos humanos en acción. Aciertos y desafíos. México: Porrúa.

Social, C. N. (2012). Anexo estadístico de pobreza en México. México: INEGI.

Unidas, A. G. (15 de diciembre de 1969). Cuestión del castigo de los criminales de guerra y de las personas que hayan cometido crímenes de lesa humanidad. (Resolución 2583, XXIV). Ginebra, Suiza: Naciones Unidas.

Unidas, A. G. (3 de diciembre de 1973). Principios de cooperación internacional en la identificación, detención, extradición y castigo de los culpables de crímenes 
de guerra, o de crímenes de lesa humanidad en su Resolución 3074. Ginebra, Suiza: Naciones Unidas.

Unidas, A. G. (1999). Declaración y Programa de Acción sobre una Cultura de Paz (p. 2). Ginebra, Suiza: Naciones Unidas.

Unidas, N. (2013). Informe del Grupo de Trabajo sobre el Examen Periódico Universal México. Ginebra suiza: ONU.

Unidas, A. G. (2014). Informe del Relator Especial sobre las ejecuciones extrajudiciales, sumarias o arbitrarias, Christof Heyns. México, D.F.: Naciones Unidas.

Unión, C. d. (1991). Ley Federal para Prevenir y Sancionar la Tortura, 1. México, D.F., México: Congreso de la Unión.

Watch, H. R. (2011). Ni seguridad, ni derechos, ejecuciones, desapariciones y tortura en la guerra contra el narcotráfico de México. México., D.F.: HRW.

Watch, H. R. (2013). Los desaparecidos de México, el persistente costo de una crisis ignorada. Estados Unidos de América: HRW. 